\title{
Boundary-GIS geoportal: advanced platform in support of participatory processes
}

\author{
M. Fetissov \& R. Aps \\ University of Tartu, Estonian Marine Institute, Tallinn, Estonia
}

\begin{abstract}
Internet GIS is defined in literature as a research and application area that utilizes the internet to facilitate the access, processing, and dissemination of geographic information and spatial analysis knowledge. Boundary-GIS geoportal is based on the ESRI ArcGIS and Silverlight technology and serves as a platform for developing different project related web applications. It is based on a concept of collaborative (participatory) processes with objectives: (1) to capture the knowledge for later use (identifying and mapping spatial resources and competing human uses), (2) to communicate the knowledge captured so it is easy to understand for other stakeholders (sense-making/communication), and (3) to connect different social groups in the construction of new localized social arrangements while the negotiation of differences between different groups is fundamental to the construction of GIS technology based boundary objects. Potential of the Boundary-GIS geoportal as an advanced platform for distributed GIS technology based applications is exemplified by demonstration of OILRISK Web and the BaltSeaPlan Web applications built on that platform. OILRISK Web serves as a tool for (1) the oil spill related contingency planning, (2) environmental risk assessment, and (3) the oil spill response decision support including the Bayesian decision ranking module. BaltSeaPlan Web serves as the "participatory GIS" platform using argumentation maps as an object based model for geographically referenced discussions that support the deliberative aspects in spatial decision-making.

Keywords: internet GIS, Boundary-GIS, participatory GIS, OILRISK Web, BaltSeaPlan Web, oil pollution risk assessment, maritime spatial planning.
\end{abstract}




\section{Introduction}

Internet GIS is defined [1] as “... a research and application area that utilizes the internet and other internetworking systems (including wireless communications and intranets) to facilitate the access, processing, and dissemination of geographic information and spatial analysis knowledge".Internet GIS are seen as client/server systems the basic functions of which - presentation, program logic, and database - are distributed between client and server while depending on the partitioning point, applications range from thin client to thick client approaches on a continuous scale [2]. Rinner [3] argue that also the Web-based spatial decision support systems (WebDSS) still wait to be subject to thorough empirical analysis, the development continues towards complex geo-processing services such as spatial decision support services (SDSServices) that are realized through chaining of basic services as follows: (1) geo-processing services, (2) service chaining, and (3) specific SDSServices. In recent literature [2] the decision support web service (DSWS) is defined as follows: a decision support web service is a service with which multiple criteria areassociated.

It is stated [4], referring to Harris et al. [5] that the term "participatory GIS" (PGIS) was coined in the mid-1990s in conjunction with a shift in focus from GIS technology and applications towards a critical evaluation of the uses of GIS in society. Rinner et al. [6] demonstrated the usefulness of the new technology of Web 2.0at hand for PGIS implementing a Google Maps-based discussion forum called Argoo Map and demonstrating its usefulness in a case study application.

Argumentation maps as an objectbasedmodel for geographically referenced discussions, introduced by Rinner [6] provide the theoretical foundations for PGIS tools thatsupport the deliberative aspects in spatial decision-making. Further developed Rinner's argumentation map model [7] defines argumentationelements and geographic reference objects as independententities distinguishing betweenreference objects which are part of the map and referenceobjects which are created by users, e.g. to mark a point locationor highlight an area.

Roderick et al. [8] report that compared with a control condition, visualization improved three aspects of negotiations: visualization support aided negotiators' convergence of perceptions of reality and had positive socioemotional consequences in terms of increasing cohesiveness. It is stated also that, groups with visualization support reached consensus more easily and were more satisfied with the process

Harvey and Chrisman [9] examine several instances of how GIS technology involves social negotiation byusing a concept of boundary objects that articulates theprocess through which technology becomes part of different social groups, and howtechnology successfully connects multiple, even opposing, perspectives.

The communities of practice also referred to as stakeholders are developing the same world view or mental model and they have a shared understanding of what the community does, of how to do it, and of how it relates to other communities and their practices [10]. As defined by Star and Griesemer [11] boundary objects are objects that are flexible enough to adapt to local needs and 
the constraints of the stakeholders employing them, yet specific enough to maintain a common identity across different interpretations. Objects (e.g. texts, maps, drawings etc) become boundary objects when they are used at the interface of different communities of practice.

Harvey and Chrisman [9] argue that "Boundary objects mediate between different groups; they do not provide a common understanding, or consensus between participants. Instead, they serve a dual function similar to that of geographic boundaries; at the same time as they serve to distinguish differences, they also supply common points of reference." It is added that the role of boundary objects can be summarized as the stabilization of certain relationships between participants while the constructed arrangement provides coherence for multiple participants and plays out various forms of power relations.

According to Harvey [12] the boundary objects play an important mediating role in interactions across information, geographic, and social spaces, and also being subject to change, these objects are more stable in interactions because of their unique characteristics that connect as well as separate different interest groups in a network. Furthermore, GIS technology connects different social groups in the construction of new localized social arrangements while the negotiation of differences between different groups is fundamental to the construction of GIS technology based boundary objects [9].

Levina [13] introduces the concept of multiparty collaborative practice that can be understood as constituting a "collective reaction-in-action" cycle through which an information systems design emerges as a result of agents producing, sharing and reflecting on explicit objects.

Aim of this paper is to present the distributed GIS technology based Boundary-GIS geoportal as an advanced platform in support of participatory processes. Issue is exemplified by demonstration of OILRISK Web and the BaltSeaPlan Web applications built on that platform.

\section{Boundary-GIS geoportal}

The Boundary-GIS geoportal (http://smartsea.eu) is based on the template of Silverlight ESRI Showcase Map Application for Microsoft Visual Studio. Map layers are developed using ArcGIS Desktop and published on the ArcGIS Server. The Boundary-GIS geoportal as a complex system embraces GIS Server, Web Server(s) and the Client(s).

GIS Server (Figure 1) is running the geo-database, which is supporting 1) feature classes (base layers, administrator's layers, user's layers and other graphics), 2) raster datasets (base layers, administrator's layers, user's layers and other graphics), 3) tables (attribute tables). GIS Server hosts Web Map Services (WMS) generated from the map documents (geo-database layers). Auxiliary database hosted on the Web Server is supporting 1) tables (authentication, users, groups, projects, scenarios etc), 2) stored procedures (managing the auxiliary tables). Web server gathers spatial information from the published WMS on the GIS servers (local/remote). 


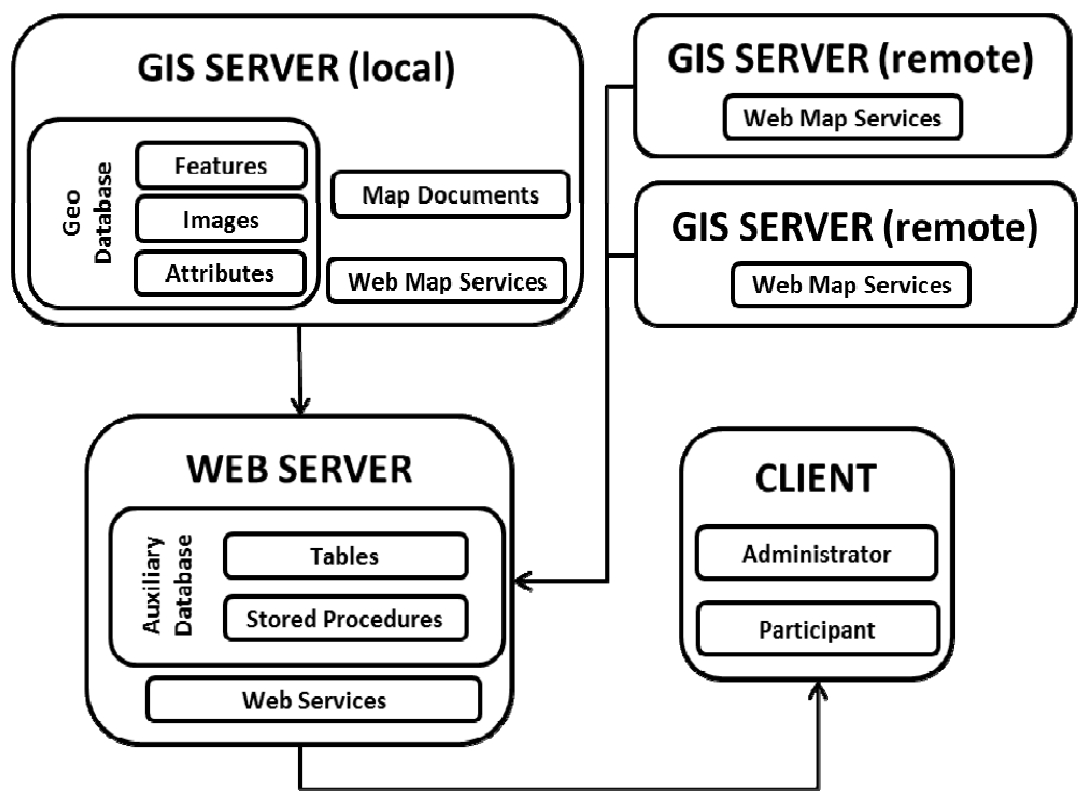

Figure 1: $\quad$ Principal architecture of the Boundary-GIS geoportal.

Client side of the geoportal (Figure 1) is supporting administrator's and the participant's activities. Administrator is responsible for 1) user management (registering users and assigning users to the groups), 2) project creation and management (adding WMS and geo-processing services to the projects), 3) project customization (setting bookmarks, adjusting the visual state of the layers like visibility and transparency, creating map tips like comments and layer descriptions, adding and editing graphic objects, attaching documents to the layers/objects/comments), 4) creation profiles for the analytical tools (spatial queries for specific attributes of layers, tools for measurement and counting, search tools).

Important task of the Boundary-GIS geoportal is to support the creation of projects consisting of ordered list of different distributed services as well as the creation of scenarios of these projects. At a time the created projects are basically using the imported information from WMS.

It is assumed that the project's resources are created and published by administrator as the WMS on the GIS server using a set of GIS Desktop programs and are added to the auxiliary database as Uniform Resource Locator (URL) addresses with additional necessary information. Different projects and communities of practice (groups) supported by the Boundary-GIS geoportal are visualized in a tree view. Assignment of users to projects and provision of services to them in general are done by the communities of practice themselves. Each community of practice has its own set of projects, members and map services assigned by the geoportal administrator or group administrator. The group members can open projects they are members of and to work with a set of 
map services assigned to the group concerned. Group members can also create their own scenarios of the project they are assigned to, edit the presentation of map services, add their own graphic layers with graphic objects, make comments, assign images and attach documents to the features/graphic objects/comments/.

The Boundary-GIS database is structured in such a way that the user with administrative role can separately create community of practice groups, projects, can register users and save URL addresses and layer information of map services. Using the assignment tool administrator can assign several users, projects and map services to the group. For example, if the user is assigned to a group it means that all projects and services which are assigned to that group become available to him.

Web services hosted on the Web Server enable the connection between Client and auxiliary database (Figure 2).

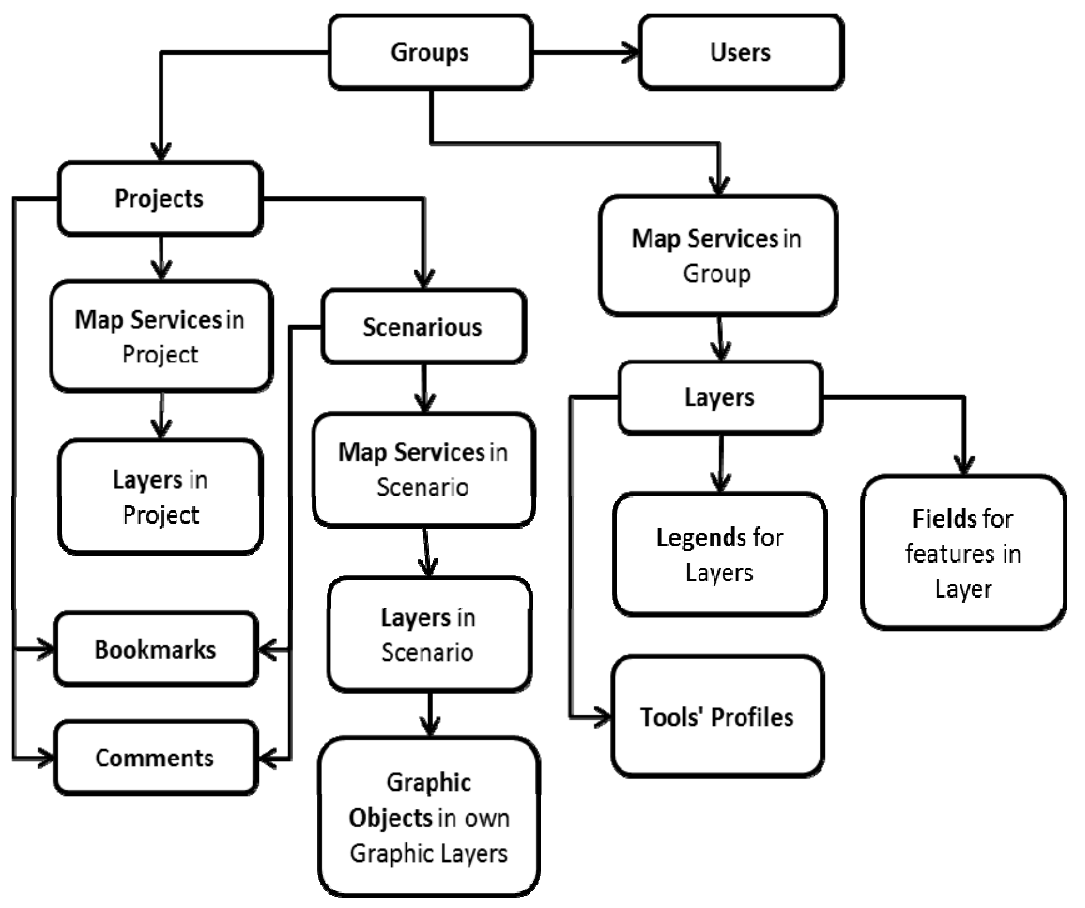

Figure 2: $\quad$ Simplified structure of the Boundary-GIS auxiliary database.

Geoportal supports all standard tools to work with map, such as: map navigation, scaling, and measurement. It provides the tools for displaying, hiding, and setting transparency of the map layers as well as for search, identification and spatial query. 


\section{OILRISK Web}

OILRISK Web serves as a tool for (1) the oil spill related contingency planning, (2) environmental risk assessment, (3) the oil spill response decision support including the Bayesian decision ranking module, and (4) as a platform enabling to track everything from daily spill positions to the locations of ships responding to the crisis as well as the real-time information collected and mapped by the state and non-governmental organizations. General architecture and integrated approach of the OILRISK Web application is presented in the Figure 3.

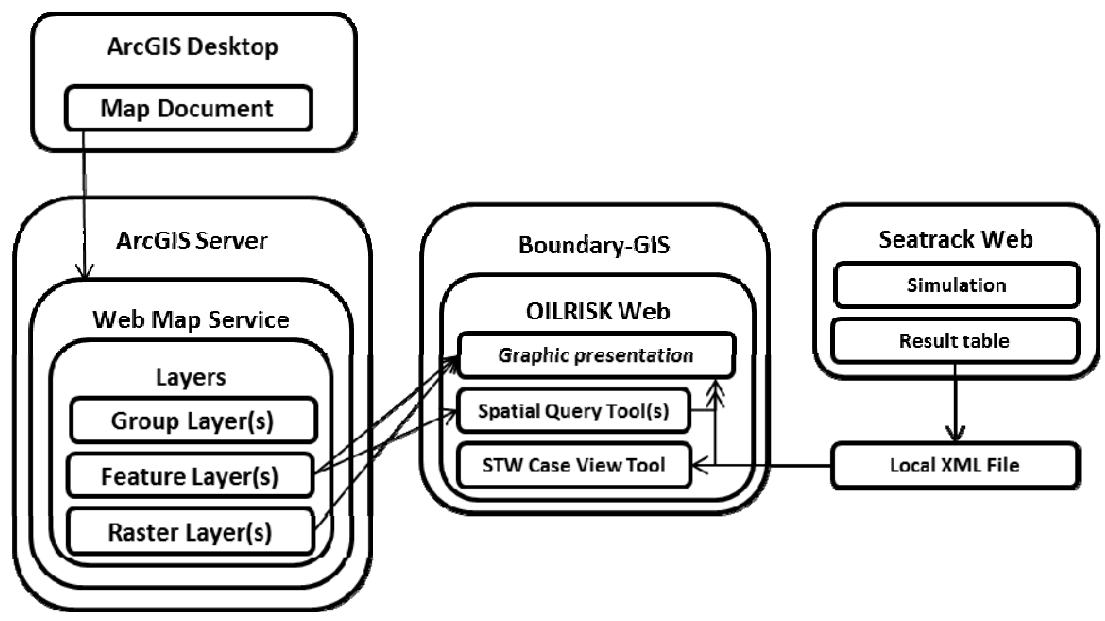

Figure 3: General architecture and integrated approach of the OILRISK Web application.

OILRISK Web application provides access for registered users to the content of the GIS resources published on the GIS server(s) as WMS. All relevant and available WMS can be imported into the OILRISK Web and analyzed in order to support the informed decisions on the oil spill response. Oil pollution related ecological sensitivity maps and/or the Environmental Sensitivity Index (ESI) map layers produced by national scientific institutions are imported as WMS into the OILRISK Web and are used in combination with the Seatrack Web simulation results to assess the threat to sensitive environment and to decide on the most appropriate response actions.

Aps et al [14] state that despite of improving navigation measures there is a growing risk for incidental oil spills and associated risk of oil pollution related ecological damage. In emergency or in a course of contingency planning 1) the Seatrack Web is activated, 2) incident related or scenario based expected drift, behavior and fate of the spilled oil is simulated (Figure 4), and 3) the simulation results are imported into the OILRISK Web modeling suite. 


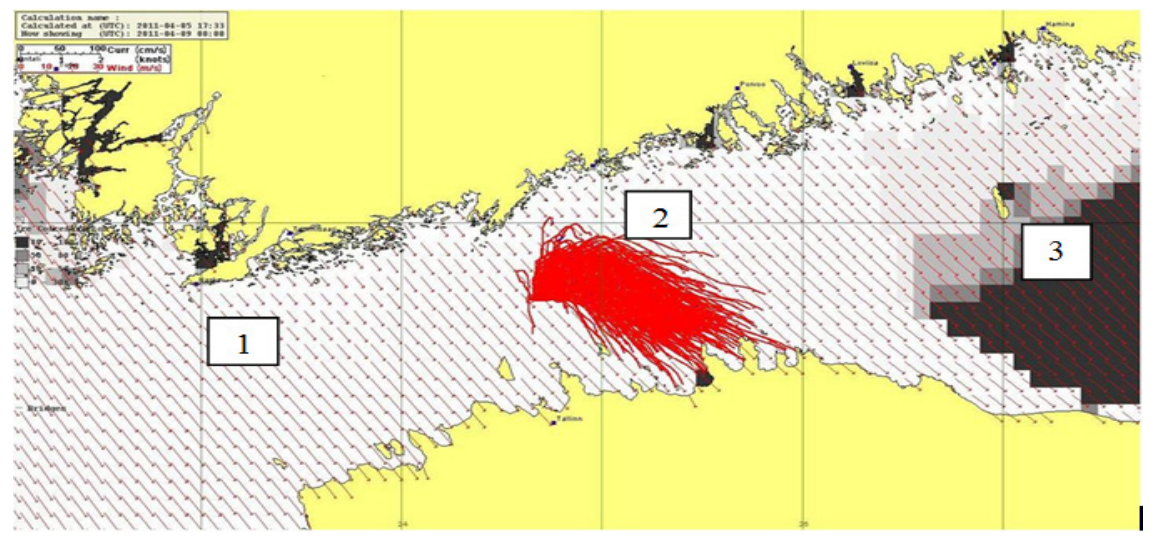

Figure 4: $\quad$ Seatrack Web calculated oil spill simulation case (5-9 April2011) in the central part of the Gulf of Finland (Baltic Sea): 1- arrows showing direction and strength of wind, 2 - oil spill footprint with weather forecast related uncertainty, and 3 - sea area covered by ice.

As a next step, the relevant environmental sensitivity WMS layers are imported into the OILRISK Web and set against footprint of expected or actual oil pollution. Figure 5 is showing the spilled oil footprint and the oiled coastline comprised of two different ESI geological coastline ranks. Pointing on a coastline returns the available data on that coastline extent and the photograph(s) of that particular coastline.

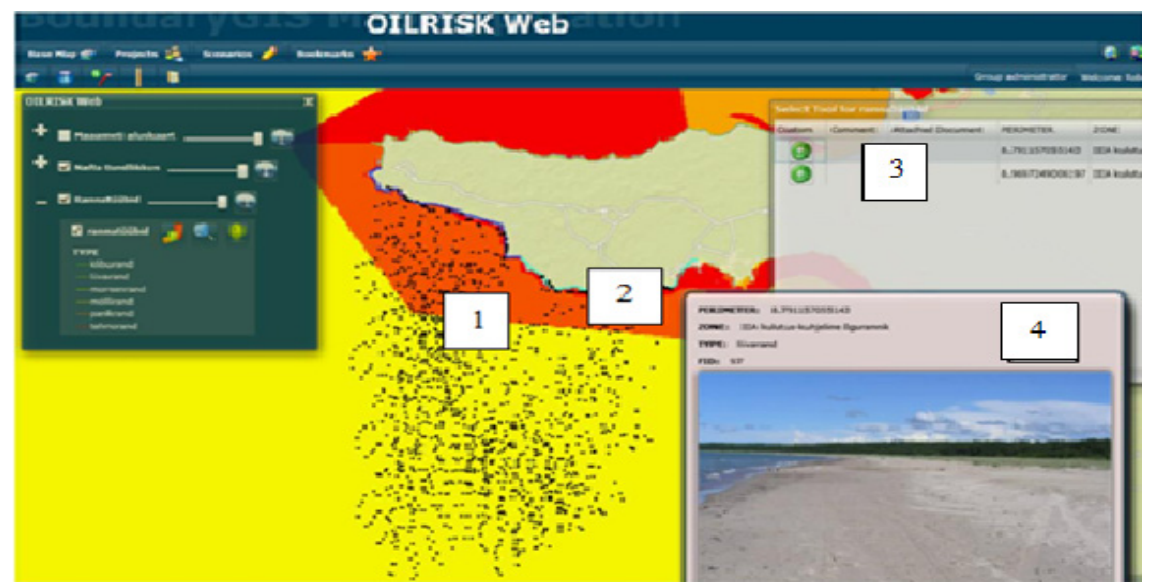

Figure 5: Footprint of spilled oil (1) and the oiled coastline comprised of two different ESI geological coastline ranks (2). Pointing on a coastline returns the available data on that coastline extent (3) and the photograph(s) of that particular coastline (4). 
Aps et al [15] argue that oil pollution related decisions on shore cleanup actions are perceived as a knowledge-based response decisions that are influenced by policy choices involving environmental, economic, social, and other concerns. Expeditious negotiated decisions on whether or not the shore cleanup is necessary or what kind and extent of shore cleanup is appropriate are usually taken on the consensual basis. Authors introduce the BBN based methodology for pair-wise comparison of potential decisions with a view to facilitate the finding a workable consensual decision on the oiled shoreline cleanup operations, on apportioning resources among a set of alternatives, and on assigning the available resources in an economic way (Figures 6 and 7).

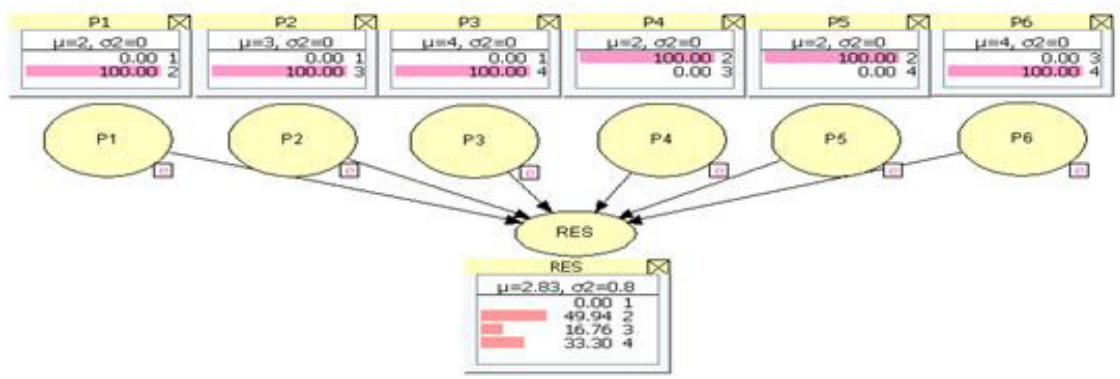

Figure 6: The result of the Bayesian ranking of the potential decision by one of response managers. P1 - P6 -different potential decision pairs, RES - probabilistic ranking of the potential decisions [15].

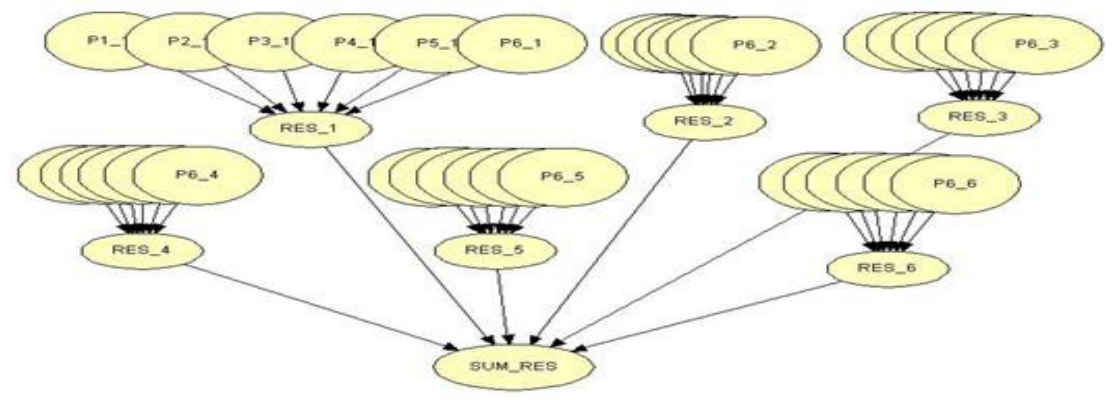

Figure 7: Ranking results of the potential oil spill response decision by 6different response managers that are further integrated into the final Bayesian ranking consensual outcome. P1_1 -P6_1 ... P1_6 P6_6 different potential decision pairs. SUM_RES - probabilistic ranking of the potential consensualdecisions [15].

\section{BaltSeaPlan web}

EU Roadmap for Maritime Spatial Planning [16] is considering MSP as a tool for improved decision-making that provides a framework for arbitrating between 
competing human activities and managing their impact on the marine environment with objective to balance sectoral interests and to achieve sustainable use of marine resources in line with the EU Sustainable Development Strategy. It is further stated that in order to achieve broad acceptance, ownership and support for implementation, it is important to involve all stakeholders, including coastal regions, at the earliest possible stage in the planning process while the stakeholder participation is also a source of knowledge that can significantly raise the quality of MSP.

BaltSeaPlan Web application is based on a concept of collaborative (participatory) process with objectives: (1) to capture the knowledge for later use (identifying and mapping spatial resources and competing human uses), (2) to communicate the knowledge captured so it is easy to understand for other stakeholders, (sense-making/communication), and (3) to connect different social groups in the construction of new localized social arrangements while the negotiation of differences between different groups is fundamental to the construction of GIS technology based boundary objects. As an example, WMS based information (wind parks and submerged cables, fishing pound-nets and yachting area) is integrated in the BaltSeaPlan Estonia web window (Figure 8).

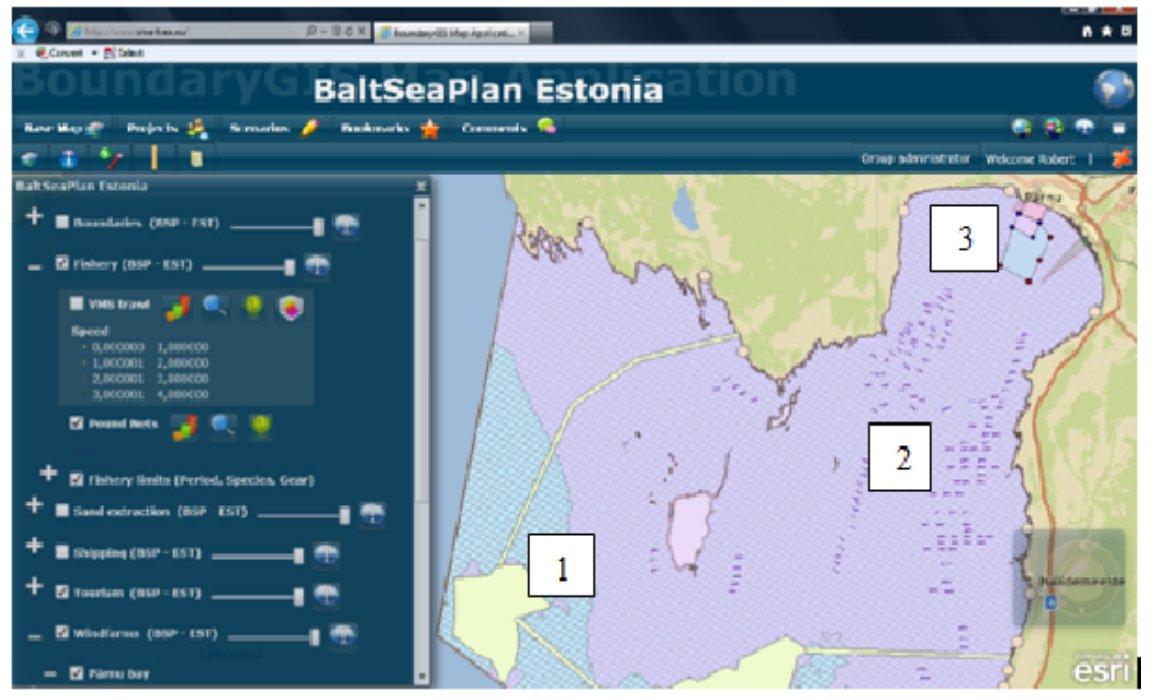

Figure 8: Wind parks and submerged cables (1), fishing pound-nets (2) and yachting area (3) as integrated in the BaltSeaPlan Estonia web window (Pärnu Bay, Gulf of Riga, Baltic Sea).

Maritime spatial planning (MSP) as defined by DEFRA [17] “... is a practical way to create and establish a more rational organization of the use of marine space and the interactions between its uses, to balance demands for development with the need to protect marine ecosystems, and to achieve social and economic objectives in an open and planned way." 
Ehler and Douvere [18] underline that MSP is first of all “... a public process of analyzing and allocating the spatial and temporal distribution of human activities in marine areas to achieve ecological, economic, and social objectives that are usually specified through a political process." It is argued further that only human activities in marine areas, not marine ecosystems or components of ecosystems can be planned and managed while the human activities can be allocated to specific marine areas by objective, e.g., development or preservation areas, or by specific uses, e.g., wind farms, offshore aquaculture, or sand and gravel mining.

Southerland and Nichols [19] state that "The governance of any geographical area, including marine spaces, is actually the management of stakeholder relationships with regard to spatial-temporal resource use in the pursuit of many sanctioned economic, social, political, and environmental objectives while good governance is based on recognition of the interests of all stakeholders, and inclusion whenever possible." It is suggested [20] that the marine space governance should be linked to the law and information including 1) allocation of resource ownership, control, stewardship and use within society, 2) regulation of resources and resource use (e.g., environmental protection, development and exploitation, rights to economic and social benefits), 3) monitoring and enforcement of the various interests; adjudication of disputes, including inclusive processes, 4) management of spatial (geographically referenced) and other types of information to support all of the above functions.

Referring to the GIS technology that connects different social groups in the construction of new localized social arrangements it is suggested [4] that in order to move from discussion support to decision support, the Internet GIS applications should be extended by a voting method for participants to express their preferences about places while without having to contribute messagesa voting system would allowfor a quick way to see how many users 'agree' or 'disagree' with acertain message or geographic location.It is added that such functionalitycould give the facilitators a quick indication of which messages ortopics are important to the participant group, and which messages or topics are supported/acceptedthrough results of the voting.BaltSeaPlan Web applies for the same purpose the Bayesian pair wise comparison tool [15] as described above in relation to the OILRISK web.

Finally, Harvey and Chrisman [9] say that GIS is “... not merely an instrument or toolbox, each particular GIS presents a unique collection of artifacts that enable multiple social groups, with divergent or even contradictory values, to mediate these differences and construct more technological artifacts. This is a dynamic process of social production, characterized by differences and contention, that repeats again and again through the construction of boundary objects."

\section{Conclusions}

Boundary-GIS is seen as universal platform for distributed GIS technology based decision support and participatory processes. At a time the created projects are 
basically using the imported data from Web Map Services to support the decision making and public participation processes that are connecting different social groups in the construction of new localized social arrangements and are facilitating the negotiation of differences between different groups.

Boundary-GIS is attempting to move from discussion support to decision support by introducing the Bayesian pair wise comparison tool with a view to facilitate the finding a workable consensual decisions.

It is expected also that the Boundary-GIS would support the multiparty collaborative practices that can be understood as constituting a "collective reaction-in-action" cycle through which an information systems design emerges as a result of agents producing, sharing and reflecting on explicit objects.

\section{Acknowledgements}

This study was supported by the Estonian Target Financing Programme SF0180104s08, Estonian Science Foundation Grant No 7609, and by the EU Baltic Sea Region Programme 2007-2013 Projects: "Introducing Maritime Spatial Planning in the Baltic Sea (BaltSeaPlan)" and "Applications ofecological knowledgein managing oil spill risk (OILRISK)".

\section{References}

[1] Peng, Z.-R., and Tsou, M.-H. Internet GIS: Distributed Geographic Information Services for the Internet and Wireless Networks. Hoboken: John Wiley \& Sons.679 p. 2003.

[2] Parimala, N., Saini, A. Decision Support Web Service. In: Distributed Computing and Internet Technology, R. Natarajan \& A. Ojo ( Eds.). Lecture Notes in Computer Science, Vol. 6536, Springer-Verlag Berlin Heidelberg, pp. 221-231. 2011.

[3] Rinner, C. Web-based Spatial Decision Support: Status and Research Directions. Journal of Geographic Information and Decision Analysis Vol. 7, No. 1, pp. 14-31. 2003.

[4] Rinner, C., Keßler, C., Andrulis, S. The use of Web 2.0 concepts to support deliberation in spatial decision-making. Computers. Environment and Urban Systems, 32, pp. 386-395. 2008.

[5] Harris, T. M., Weiner, D., Warner, T. A., \& Levin, R. Pursuing social goals through participatory geographic information systems Redressing South Africa's historical political ecology. In: J. Pickles (Ed.), Ground truth: The social implications of geographic information systems (pp. 196222). New York: Guilford Press. 1995.

[6] Rinner, C. Argumentation maps: GIS-based discussion support for on-line planning. Environment and Planning B: Planning and Design, 28(6), pp. 847-863. 2001.

[7] Rinner, C. Argumentation mapping in collaborative spatial decision making.In: S. Dragicevic \& S. Balram (Eds.), Collaborative GIS (pp. 85102). Idea Group Publishing. 2006. 
[8] Roderick I. Swaab, Tom Postmes, Peter Neijens, Marius H. Kiers, and Adrie C. M. Dumay. Multiparty Negotiation Support: The Role of Visualization's Influence on the Development of Shared Mental Models. J. Manage. Inf. Syst. 19, 1, pp. 129-150. 2002.

[9] Harvey, F., Chrisman, N. Boundary objects and the social construction of GIS Technology. Environment and Planning, Vol. 30, pp. 1683-1694. 1998.

[10] Brown, J.S., Duguid,P. Organizing Knowledge. California Management Review, Vol. 40, pp. 28-44.1998.

[11] Star, S.L., Griesemer, J.R. Institutional ecology, 'translations', and boundary objects: amateurs and professionals in Berkeley's Museum of Vertebrate Zoology. Social Studies of Science, 19, pp. 387-420.1989.

[12] Harvey, F. Of Boundary Objects and Boundaries: Local Stabilization of the Polish CadastralInfrastructure.The Information Society, 25 (5), pp. 315327. 2009.

[13] Levina, N. Collaborating on multiparty information systems development projects: a collective reflection in action view. Information systems Research, vol. 16, n 2, pp. 109-130. 2005.

[14] Aps, R., Ambjörn, C., Fetissov, M., Karjalainen, M., Kotta, J. Kuikka., S. OILRISK Web: Advanced Tool for Enhancing Spill Response Decisionmaking in the Baltic Region. In: Proceedings of the 2011 WMU-IMO Conference on Oil Spill Risk Management Preparedness, Response and Contingency Planning in the Shipping and Offshore Industries, 7-9 March, Malmö, Sweden. 2011. In print.

[15] R. Aps, N. Sawano, S. Hamada, M. Fetissov. Bayesian inference in oil spill response management. In: C.A. Brebbia (Ed.), Risk Analysis VII \& Brownfields. WIT Press Southampton, Boston, pp. 32-46. 2010.

[16] EC. Communication from the Commission: Roadmap for Maritime Spatial Planning: Achieving Common Principles in the EU. COM(2008) 791 final, Brussels, 12 p. 2008.

[17] DEFRA. Managing Our Marine Resources: the Marine Management Organization. Department of Environment, Food and Rural Affairs (Defra), London, UK. 2009, 38 p.

[18] Ehler, C., Douvere, F. Marine Spatial Planning: a step-by-step approach toward ecosystem-based management. IOC Manual and Guides No. 53, ICAM No. 6. Paris: UNESCO, 99 p. 2009.

[19] M.D. Sutherland, S. Nichols. Administering Marine Spaces: International issues. FIG publication 36, Copenhagen, 16 p. 2006.

[20] S. Nichols, D. Monahan, M.D. Sutherland. Good Governance of Canada's Offshore and Coastal Zone: Towards and understanding of the Maritime Boundary Issues. Geomatica, Vol. 54, No. 4, pp. 415-424.2000. 